\title{
Leshkowich, Ann Marie. Essential trade: Vietnamese women in a changing marketplace. Honolulu: University of Hawai'i Press, 2014, xi + 251 pp.
}

El libro en solitario de Ann Marie Leschkowich, Essential trade: Vietnamese women in a changing marketplace (ganador del premio Harry J. Benda de la Association of Asian Studies en 2016), se basa en la tesis que escribió sobre las mujeres comerciantes de Bến Thành, un conocido mercado en la Ciudad Ho Chi Minh (Saigón). Dentro de sus líneas de investigación — género, memoria e identidad en Vietnam-, su libro interactúa con las críticas de los esencialismos de género planteadas por Foucault y Butler, así como las maneras en que Spivak ha argumentado que dichos esencialismos pueden ser utilizados por los actores sociales para poder controlar las maneras en que se hacen efectivos. Asimismo, Essential trade explora las maneras en que los individuos negocian categorías de género y clase para prosperar dentro de los marcos de gubernamentalidad foucaultiana impuestos por la República Socialista de Vietnam.

Enfocándose en las vidas, categorías político-culturales y las expectativas que las comerciantes del mercado Bến Thành deben negociar, Essential trade nos ofrece una profunda perspectiva etnográfica de cómo la modernidad colonial, revolución socialista, y reformas de mercado han afectado su cultura y vida cotidiana, así como la manera en que estas comerciantes a su vez influyen en la cultura familiar y las concepciones populares de la moda y el comercio. $\mathrm{Y}$ aquí yacen las diferentes capas contenidas en el título del libro. El comercio realizado por estas mujeres no solo es esencial en la medida en que los ingresos generados por este son necesarios para sostener a sus familias, sino que también está impregnado de nociones esencialistas de lo que la condición de mujer y comerciante debería parecer. Los atributos considerados necesarios para el éxito como pequeña comerciante (tiểu thuoong) — ser capaz de «hablar tonterías» (nói $x a o$ ) al negociar un precio, así como la voluntad de siempre buscar las mejores transacciones posibles - son vistos como esencialmente femeninos en la cultura vietnamita «tradicional», según la cual se espera que los hombres busquen empleos más dignos, como funcionarios estatales o académicos.

Asimismo, estas pequeñas comerciantes tienen que asegurarse de seguir aparentando permanecer en dicha categoría — pese a cualquier éxito financiero-, debido a la seguridad que les provee, ya que la visión socialista del Estado vietnamita considera a los pequeños comerciantes - especialmente las mujeresesencialmente como miembros de la clase proletaria que buscan suplementar sus ingresos, en lugar de capitalistas propietarios de los medios de producción y, por 
ende, explotadores. En estos dos sentidos, estas mujeres están comerciando en el marco de esencias que deben cuidarse de no perturbar.

Si bien el análisis de Leshkowich se enfoca mayormente en el período de la década de 1990 al presente, se remonta a la época colonial y a la construcción del mercado Bến Thành en 1914 para proveer profundidad histórica. Como parte del proyecto «modernizador» de la administración colonial de Cochinchina, podemos ver cómo este nuevo mercado fue considerado un «paso adelante» en la mission civilisatrice francesa, pero fue reinterpretado como un mercado «tradicional» poco después. Este mercado «tradicional» sería visto con creciente sospecha por el régimen socialista tras la captura de Saigón en 1975, lo cual llevó eventualmente a su expropiación y transformación en una cooperativa. Para la década de 1980, sin embargo, políticas de reforma (Đổi mói i) llevaron a que se volviera a privatizar, lo cual en la práctica fue meramente una sanción estatal de las realidades que ya se vivían en el mercado. Este es el contexto general en el que las comerciantes del mercado Bến Thành tuvieron que negociar las esencialistas categorías culturales y políticas que se les impusieron.

El libro de Leshkowich es especialmente valioso para entender los espacios liminares en que las mujeres deben operar en la Vietnam meridional actual. Por un lado, está la presión estatal de construir una economía fuerte y moderna, simbolizada por los nuevos rascacielos de la ciudad Ho Chi Minh. No obstante, pese al deseo por lo «moderno» —especialmente los patrones de consumo típicos de la clase media-, hay una profunda sospecha respecto de dicha clase social. Como resultado, las tiểu thuoong tienen que aferrarse a la categoría y esencia de pequeñas comerciantes, quienes solo complementan los ingresos de sus esposos mientras intentan cuidar a sus familias, adecuándose así a las esencializaciones vietnamitas «tradicionales» del papel de la mujer, así como a la promoción socialista «moderna» del empoderamiento femenino e igualdad de géneros. Asimismo, Leshkowich muestra los mecanismos mediante los cuales las tiểu thuong intentan reducir el riesgo de ser percibidas por el gobierno como capitalistas explotadoras. Recurren a redes de parentesco para obtener mano de obra y así contener su expansión dentro de la categoría de «negocio familiar», el cual les ayuda evitar una atención excesiva por el gobierno. La autora también muestra cómo las familias comerciantes sistemáticamente minimizan sus ingresos — classing down (184) - y, especialmente, sus capacidades productivas en la forma de pequeñas fábricas, mientras que resaltan sus hábitos de consumo, tales como la compra de motocicletas o el envío de sus hijos a estudiar a Australia. Es decir, classing up (181). Están intentando alcanzar la «modernidad»y, al mismo tiempo, rechazar el estigma de la explotación capitalista. 
En líneas generales, la forma en que las mujeres comerciantes de Bến Thành negocian las ventajas y desventajas de los esencialismos de género podría resultar de interés para quienes estudien casos que pueden resultar análogos en los Andes. En este sentido, sería esencial ponerlo en diálogo con textos como Between field and cooking pot: the political economy of marketwomen in Peru, de Florence E. Babb, y Peruvian Street lives: culture, power, and economy among market women of Cuzco, de Linda Seligmann. Una perspectiva comparada de las estrategias de supervivencia y movilidad social puestas en prácticas por estas mujeres comerciantes en mercados de países en vías de desarrollo puede servir para enmarcar los debates en torno a la posición de la mujer en contextos de capitalismo neoliberal abierto o asolapado. Con una etnografía de primera clase e intervenciones claves en los debates antropológicos actuales, Essential trade es también un excelente punto de entrada al estudio de Vietnam.

Jorge Bayona

University of Washington (Seattle)

jbayona@uw.edu

\section{Resumen}

Dentro de las líneas de investigación de género, memoria e identidad, el libro de Ann Marie Leshkowich, Essential trade: Vietnamese women in a changing marketplace ofrece una profunda perspectiva etnográfica de cómo modernidad colonial, revolución socialista, y reformas de mercado han afectado la cultura, vida cotidiana, en especial la cultura familiar y concepciones populares de la moda y el comercio, modificando también las nociones de lo que la condición de mujer y comerciante debería parecer. Leshkowich muestra los espacios liminares en que deben operar y las formas en que las mujeres de Ben Thanh negocian las ventajas y desventajas de los esencialismos de género.

Palabras clave: etnografía, mercado, mujeres, empoderamiento, especialización

Keywords: ethnography, trade, women, empowerment, essentialization 